\title{
Rapid decrease of necrotic core after acute myocardial infarction ${ }^{*}$
}

\author{
Jun Ho Lee ${ }^{1}$, Eun-Seok Shin ${ }^{1 \#, ~ S h i n-J a e ~ K i m ~}{ }^{1}$, Jong Min Kim ${ }^{1}$, Jung Won Hwang ${ }^{1}$, \\ Hector M. Garcia-Garcia ${ }^{2}$, Patrick W. Serruys ${ }^{2}$

\begin{abstract}
${ }^{1}$ Department of Cardiology, Ulsan University Hospital, University of Ulsan College of Medicine, Ulsan, Korea ${ }^{2}$ Department of Interventional Cardiology, Thoraxcenter, Erasmus Medical Center, Rotterdam, The Netherlands Email: ${ }^{\text {ses@uuh.ulsan.kr }}$
\end{abstract}

Received 3 March 2012; revised 31 March 2012; accepted 2 April 2012

\begin{abstract}
It is well known that the increase of necrotic core in previous atherosclerotic coronary artery disease is one of the conditions of vulnerable plaque. However, it is not known how fast necrotic core could decrease in a vulnerable plaque. We had 2 patients who had suffered from acute myocardial infarction and had large amount of necrotic core in their culprit lesions at baseline, which decreased markedly within 7 days. Also, they were clinically stable and asymptomatic over 1 year follow-up. It is first report to show markedly decrease of necrotic core amount within only 7 days in culprit lesions of $\mathbf{2}$ cases of acute myocardial infarction with angiographically minimal lesions.
\end{abstract}

Keywords: Vulnerable Plaque; IVUS; Acute Myocardial Infarction; Variant Angina

\section{INTRODUCTION}

It is well known that acute myocardial infarction or sudden death may occur in patients with variant angina, even with no or insignificant organic coronary stenosis [1]. Moreover, most of variant angina has lots of plaque, though it has insignificant stenosis on angiogram. Some clinical studies have shown that patients with variant angina treated with calcium blockers rarely experience cardiac events [2,3]. However, several angiographic studies concerning the relationship between vasospasticity and the acceleration of atherosclerosis have yield conflicting results [4-8]. These two patients showed unchanged coronary angiogram and plaque burden at follow-up 7 days later though one patient had complained intermittent chest pain during that period.

\footnotetext{
*All authors have approved the final manuscript, which has not been published and is not under consideration elsewhere. We declare that there is no conflict of interest for any author.

"Corresponding author.
}

\section{CASES}

\subsection{Case 1}

A 39-year-old man with a history of hypertension and smoking habit was brought to the emergency room because he suddenly developed resting chest pain lasting for 30 minutes. The initial electrocardiogram at emergency room showed ST-segment elevation in the precordial leads, which promptly normalized after sublingual nitroglycerin administration (Figure 1). Cardiac enzyme levels were elevated. CK-MB and Troponin T levels were $166.5 \mathrm{ng} / \mathrm{mL}(0-3.6 \mathrm{ng} / \mathrm{mL})$ and $0.89 \mathrm{ng} / \mathrm{mL}(0$ - $0.1 \mathrm{ng} / \mathrm{mL}$ ), respectively. Emergent coronary angiography revealed a minimal lesion in the middle portion of the left anterior descending (m-LAD) artery (Figure 2) and intermediate stenosis of proximal right coronary artery (p-RCA). We performed intravascular ultrasound (IVUS) after $200 \mu \mathrm{g}$ nitroglycerin intracoronary injection and $\mathrm{m}$-LAD of culprit lesion revealed minimal lumen cross-sectional area of $7.1 \mathrm{~mm}^{2}$ with plaque burden of 68\% (Figure 3). After 7 days, we performed follow-up coronary angiogram because he had intermittent resting chest pain. His follow-up coronary angiogram was unchanged and IVUS showed minimal lumen cross-sectional area of $6.9 \mathrm{~mm}^{2}$ with plaque burden of $64 \%$ (Figure 3). However, at baseline the necrotic core volume was $68.1 \mathrm{~mm}^{3}$ that had decreased to $24.4 \mathrm{~mm}^{3}$ after 7 days (Table 1). In contrast to m-LAD, p-RCA of nonculprit had necrotic core of $11.0 \mathrm{~mm}^{3}$ at baseline and $12.3 \mathrm{~mm}^{3}$ at follow-up. The patient was treated with calcium channel blocker with oral nitrate and he was free from angina for the last 12 months.

\subsection{Case 2}

A 37-year-old man of current smoker was admitted to emergency room because of suddenly developed resting chest pain in the preceding 5 hours. At admission his chest pain has partially subsided because he took sublin- 

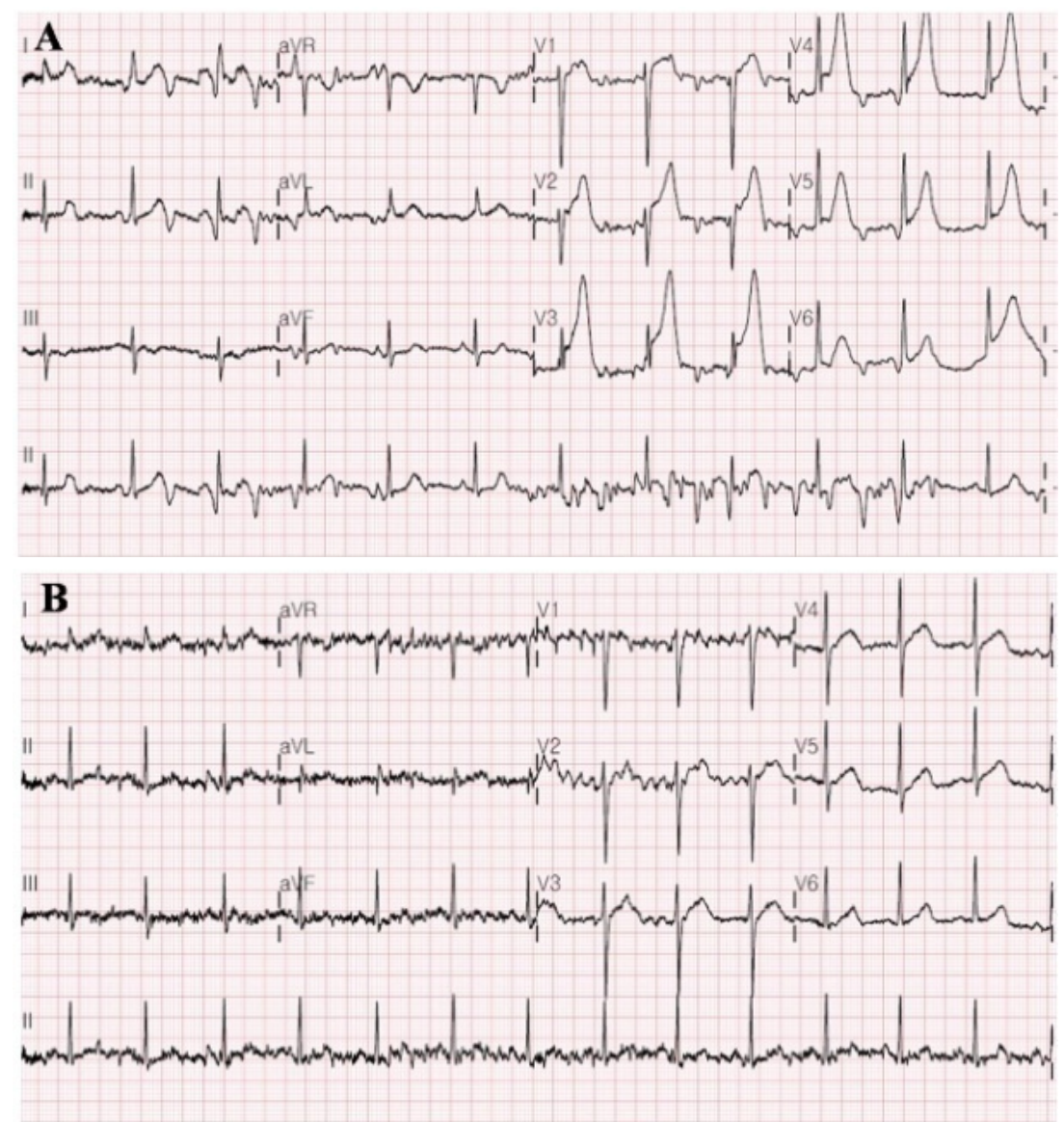

Figure 1. Case 1 (A) Baseline electrocardiogram at admission to the emergency room. ST-segment elevation is shown in precordial leads; (B) Normalized ST-segment after apply sublingual nitroglycerin.
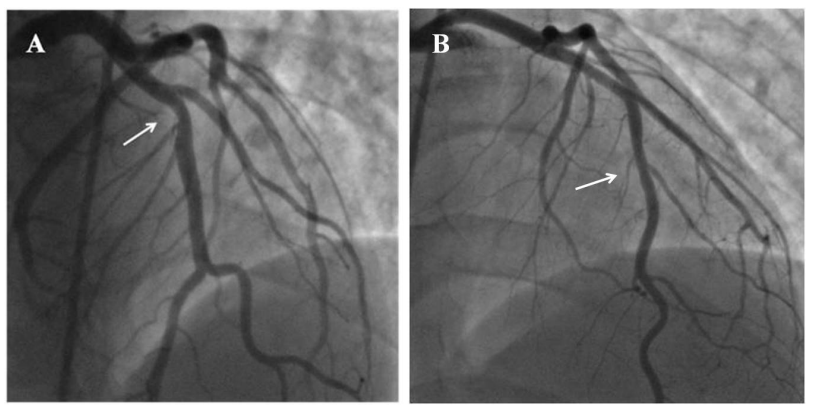

Figure 2. Baseline coronary angiograms (A) Case 1: Minimal lesion is seen in the middle of left anterior descending artery; (B) Case 2: Except for a very mild luminal abnormality in the proximal left anterior descending artery, no abnormalities are seen.

gual nitroglycerin at transferring hospital. His initial electrocardiogram appeared to be normal. His CKMB was $112.78 \mathrm{ng} / \mathrm{ml}(0-3.6 \mathrm{ng} / \mathrm{ml})$ and Troponin $\mathrm{T}$ was $2.26 \mathrm{ng} / \mathrm{ml}(0-0.1 \mathrm{ng} / \mathrm{ml})$. His echocardiogram showed focal akinesia of true apical wall with preserved LV systolic function. We performed elective coronary angiogram after 2 days. He had minimal lesions in m-LAD

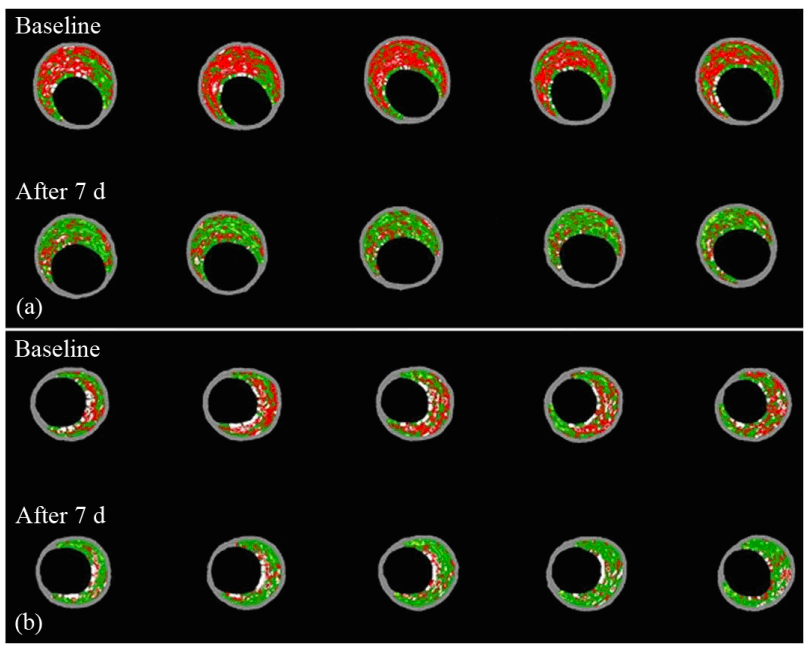

Figure 3. (a) Case 1; (b) Case 2: Serial VH-IVUS images. Comparing baseline and the images after 7 days, they show much decreased necrotic core after 7 days in culprit lesions of both cases.

(Figure 2). We performed vasospasm test with intracoronary ergonovine injection. While right coronary ar- 
Table 1. Comparing baseline and follow-up IVUS and Virtual Histology volumetric data in culprit lesions.

\begin{tabular}{lcccc}
\hline & \multicolumn{2}{c}{ Case 1 } & \multicolumn{2}{c}{ Case 2 } \\
\cline { 2 - 5 } & \multicolumn{1}{c}{ Baseline } & After 7 days & Baseline & After 7 days \\
\hline Lumen volume, $\mathrm{mm}^{3}$ & 339.6 & 318.2 & 80 & 84.4 \\
Vessel volume, $\mathrm{mm}^{3}$ & 659.1 & 624.1 & 156.7 & 157.8 \\
Plaque volume, mm & 319.5 & 305.9 & 76.8 & 73.4 \\
Lesion length, mm & 29.2 & 32.7 & 10 & 10.1 \\
Fibrous, $\mathrm{mm}^{3}$ (\%) & $115.3(57)$ & $132.8(68)$ & $19.6(49)$ & $24.5(66)$ \\
Fibrofatty, $\mathrm{mm}^{3}$ (\%) & $13.9(7)$ & $34.4(18)$ & $0.9(2)$ & $1.2(3)$ \\
Calcium, $\mathrm{mm}^{3}(\%)$ & $5.7(3)$ & $3.4(2)$ & $5.8(15)$ & $4.5(12)$ \\
Necrotic core, $\mathrm{mm}^{3}$ (\%) $68.1(33)$ & $24.4(12)$ & $14.1(35)$ & $7.3(19)$ \\
\hline
\end{tabular}

tery had negative result, LAD was positive with a focal dynamic narrowing up to 90 percent of the vessel accompanied by chest pain with ST-segment elevation on the precordial leads. After $200 \mu \mathrm{g}$ of nitroglycerin intracoronary injection, we performed IVUS and it revealed minimal lumen cross-sectional area of $5.5 \mathrm{~mm}^{2}$ with plaque burden of $66 \%$ (Figure 3) in m-LAD. We performed follow-up coronary angiogram after 7 days, which was not changed. We performed IVUS, which showed minimal lumen cross-sectional area of $6.3 \mathrm{~mm}^{2}$ with plaque burden of $61 \%$ (Figure 3). The necrotic core volume was $14.1 \mathrm{~mm}^{3}$ in the whole lesion length at baseline, but it was much decreased to $7.3 \mathrm{~mm}^{3}$ after 7 days (Table 1). The patient was treated with medication of calcium channel blocker with oral nitrate and he has been free from angina for 16 months.

\section{DISCUSSION}

The most common histological appearance of patients with variant angina is neointimal hyperplasia [1]. In the first case, p-RCA of non-culprit lesion had a plaque type of fibroatheroma with VH-IVUS that had relatively small amount of necrotic core. However, m-LAD of its culprit lesion showed large amount and conglomerated necrotic core. It is well known that the increase of necrotic core in previous atherosclerotic coronary artery disease is one of the conditions of vulnerable plaque [9]. But how the increase of necrotic core in variant angina affects the provocation of spasm and clinical outcome remains unclear. Also, it is uncertain, though intriguing, why more than $50 \%$ of necrotic core decrease in a week and thereafter the patients remained symptoms free.

Coronary angioscopic studies in patients with variant angina have revealed a high frequency of intimal injuries as intimal flap, hemorrhage, and ulcer at the site of vasospasm that were not detected by the simultaneous performance of coronary angiography [10]. Recent studies showed that intraplaque hemorrhage is an important process in the progression of asymptomatic plaques into high-risk unstable lesions [11]. Red blood cell membranes are rich in phospholipids and free cholesterol, and their accumulation within plaques plays a key role in promoting lesion instability through necrotic core expansion and inflammatory cell infiltration [12]. If this would have been intraplaque hemorrhage that can be absorbed quickly as like developed fast. However, there is no data how intraplaque hemorrhage looks like in VH-IVUS. So, we have to concern about this limitation of VH-IVUS that intraplaque hemorrhage may mislead the necrotic core in VH-IVUS. In addition, it is not known whether plaque composition could decrease rapidly only in patients with variant angina or not.

Another we should be concerned that reprobucibility of VH-IVUS is limited. But, recent some studies showed VH-IVUS has good or acceptable reproducibility. One study showed that the Spearman rank-order correlation coefficients between Pullback trials 1 and 2 for the fibrous, fibrofatty, necroticcore, and dense calcium measurements were $0.97,0.90,0.90$ and 0.90 , respectively, and therefore evidenced a high level of reproducibility [13]. Regarding the inter-catheter relative difference, the other study also demonstrated acceptable reproducibility of VH-IVUS with the limits of agreement for calcium, fibrous, fibrofatty and necrotic core area measurements were $0.22,-0.25 \mathrm{~mm}^{2} ; 1.02,-0.71 \mathrm{~mm}^{2} ; 0.61,-0.65$ $\mathrm{mm}^{2}$; and $0.43,-0.38 \mathrm{~mm}^{2}$ respectively [14]. Also in volumetric measurements, another study showed relatively high reproducibility of VH-IVUS. For fibrous, fibrofatty, calcium, and necrotic-core volumes the relative measurement differences $1.40 \%+/-4.1 \% ; 1.26 \%$ +/- 6.7\%; $2.66 \%+/-7.4 \%$; $0.85 \%+/-4.4 \%$, respectively in intra-observer comparison, repeated pullback (p = NS for all) [15]. We measured 2 cases all with one analyzer. Therefore, though we consider the difference of inter-catheter variability, we could not say that the degree of change of necrotic core at follow-up, more than $50 \%$, was accident.

However, a word of caution should be mentioned, these are just two cases, and further study is needed to observe how the tissue characterization can help us to evaluate the culprit lesions in patients with variant angina that eventually developed an AMI.

\section{REFERENCES}

[1] Hiromasa, S., Sachio, K., Tadanori, A., et al. (1999) Histological evaluation of coronary plaque in patients with variant angina: Relationship between vasospasm and neointimal hyperplasia in primary coronary lesions. Journal of the American College of Cardiology, 33, 198-205. doi:10.1016/S0735-1097(98)00520-8

[2] Severi, S., Davies, G., Maseri, A., et al. (1980) LongTerm prognosis of "variant" angina with medical treatment. American Journal of Cardiology, 46, 226-232. 


\section{doi:10.1016/0002-9149(80)90062-4}

[3] Nakamura, M., Takeshita, A. and Nose, Y. (1987) Clinical characteristics associated with myocardial infarction, arrhythmias, and sudden death in patients with vasospastic angina. Circulation, 75, 1110-1116. doi:10.1161/01.CIR.75.6.1110

[4] Maseri, A., L’Abbate, A., Baroldi, G., et al. (1978) Coronary vasospasm as a possible cause of myocardial infarcttion: A conclusion derived from the study of preinfarction angina. New England Journal of Medicine, 299, 12711277. doi:10.1056/NEJM197812072992303

[5] Marzilli, M., Goldstein, S., Trivella, MG., et al. (1980) Some clinical considerations regarding the relation of coronary vasospasm tocoronary atherosclerosis: A hypothetical pathogenesis. American Journal of Cardiology, 45, 882-886. doi:10.1016/0002-9149(80)90135-6

[6] Nobuyoshi, M., Tanaka, M., Nosaka, H., et al. (1991) Progression of coronary atherosclerosis: Is coronary spasm related to progression? Journal of the American College of Cardiology, 18, 904-910. doi:10.1016/0735-1097(91)90745-U

[7] Kaski, J.C., Tousuolis, D., McFadden, E., et al. (1992) Variant angina pectoris: Role of coronary spasm in the development of fixed coronary obstructions. Circulation, 85, 619-626.

[8] Ozaki, Y., Keane, D. and Patrick, W.S. (1995) Progression and regression of coronary stenosis in the long-term follow-up of vasospastic angina. Circulation, 92, 24462456.

[9] Thim, T., Hagensen, M.K., Bentzon, J.F. and Folk E. (2008) From vulnerable plaque to atherothrombosis. Jour- nal of Internal Medicine, 263, 506-516. doi:10.1111/j.1365-2796.2008.01947.x

[10] Etsuda, H., Mizuno, K., Arakawa, K., et al. (1993) Angioscopy in variant angina: Coronary artery spasm and intimal injury. Lancet, 342, 1322-1324. doi:10.1016/0140-6736(93)92245-O

[11] Kolodgie, F.D., Gold. H.K., Burke, A.P., et al. (2003) Intraplaque hemorrhage and progression of coronary atheroma. New England Journal of Medicine, 349, 23162325. doi:10.1056/NEJMoa035655

[12] Virmani, R., Kolodgie, F.D., Burke, A.P., et al. (2005) Atherosclerotic plaque progression and vulnerability to rupture; angiogenesis as a source of intraplaque hemorrhage. Atherosclerosis, Thrombosis and Vascular Biology, 25, 2054-2061. doi:10.1161/01.ATV.0000178991.71605.18

[13] Prasad, A., Cipher, D.J., Prasad, A., et al. (2008) Reproducibility of intravascular ultrasound virtual histology analysis. Cardiovascular Revascularization Medicine, 9, 71-77. doi:10.1016/j.carrev.2007.11.004

[14] Rodriguez-Granillo, G.A., Vaina, S., García-García, H.M., et al. (2006) Reproducibility of intravascular ultrasound radiofrequency data analysis: Implications for the design of longitudinal studies. The International Journal of Cardiovascular Imaging, 22, 621-631. doi:10.1007/s10554-006-9080-0

[15] Hartmann, M., Mattern, E.S., Huisman, J., et al. (2009) Reproducibility of volumetric intravascular ultrasound radiofrequency-based analysis of coronary plaque composition in vivo. International Journal of Cardiovascular Imaging, 25, 13-23. doi:10.1007/s10554-008-9338-9 